\title{
Community and home gardens increase vegetable intake and food security of residents in San Jose, California
}

by Susan Algert, Lucy Diekmann, Marian Renvall and Leslie Gray

As of 2013, 42 million American households were involved in growing their own food either at home or in a community garden plot. The purpose of this pilot study was to document the extent to which gardeners, particularly less affluent ones, increase their vegetable intake when eating from either home or community garden spaces. Eighty-five community gardeners and 50 home gardeners from San Jose, California, completed a survey providing information on demographic background, self-rated health, vegetable intake and the benefits of gardening. The gardeners surveyed were generally low income and came from a variety of ethnic and educational backgrounds. Participants in this study reported doubling their vegetable intake to a level that met the number of daily servings recommended by the U.S. Dietary Guidelines. Growing food in community and home gardens can contribute to food security by helping provide access to fresh vegetables and increasing consumption of vegetables by gardeners and their families.

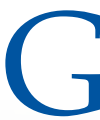
ardeners today represent a broad cross section of the U.S. population. The most often cited reasons for gardening include cost savings and a desire to improve the taste, nutrition and quality of the fruits and vegetables consumed (National Gardening Association 2014). A high vegetable intake is associated with a healthy diet that is lower in calories and higher in fiber. Yet national health surveys indicate that all

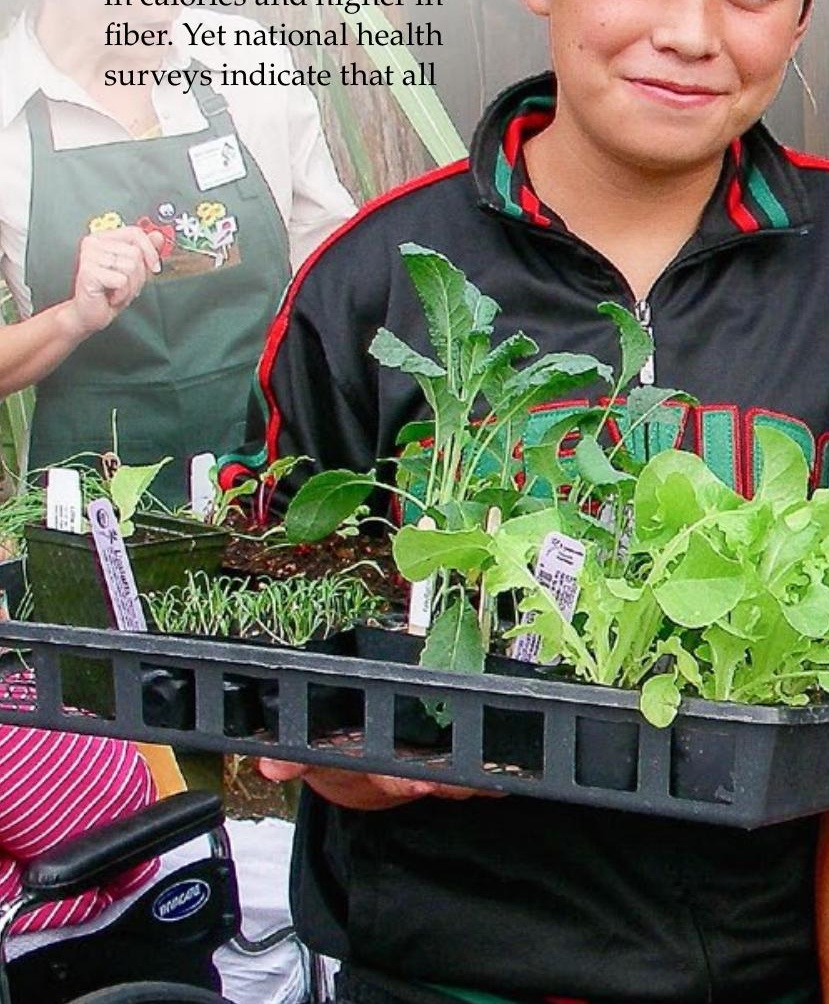

Americans are eating fewer vegetables than are recommended for optimal health (Haack and Byker 2014; USDA DHHS 2010), and vegetable consumption is particularly low among low-income populaet al. 2012).
Increasing access to and consumption of fresh vegetables is an important public health goal. Gardening can contribute to food security at all income levels by providing access to fresh, culturally acceptable produce and encouraging a more nutritious diet. Food security is defined as "access by all people at all times to enough food for an active and healthy life" (Coleman-Jensen et al. 2012) and is a concept that encompasses food's quantity, quality and cultural acceptability. Cultural acceptability acknowledges that customary, preferred and prohibited foods differ between groups.

Community gardens have been shown to increase gardeners' intake of fresh vegetables in the United States (Algert et al. 2014), potentially providing access to people who are unable to garden where they live. However, many community gardens have long wait lists and are limited in scope and scale (Public Health Law and

Online: http://dx.doi.org/10.3733/ca.v070n02p77

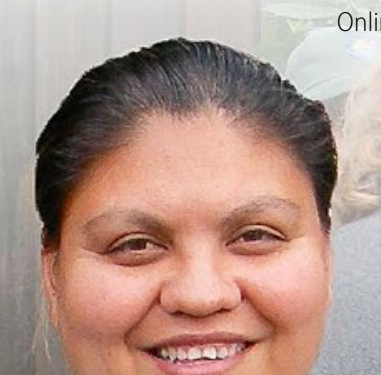

The La Mesa Verde program in San Jose helps low-income families to establish their own vegetable gardens. A pilot study found that gardening in either a community or backyard space made a significant contribution to gardeners' daily vegetable intake. 
Community gardens have been shown to increase gardeners' intake of fresh vegetables.

Policy 2010). Research on the ability of home gardens to increase intake of fresh vegetables is sparse (Taylor and Lovell 2014), partially due to home gardens' informal and private nature.

As an extensive and popular land use, home food gardens make up a much larger portion of the total area of urban land in food production than public sites of urban agriculture (Carney et al. 2012; Kortright and Wakefield 2010; Taylor and Lovell 2012). For the many people who do not have access to a community garden, gardening at home can be a strategy for improving access to fresh produce. Home gardens may also enhance food security in communities where fresh fruits and vegetables are not available either because of their cost or a lack of retail outlets.

Increasingly, cities, nonprofits and individuals are interested in gardening as a way to improve access to healthy food. A number of programs in California, including La Mesa Verde (LMV) in San Jose, are assisting low-income families with establishing their own vegetable gardens. As of

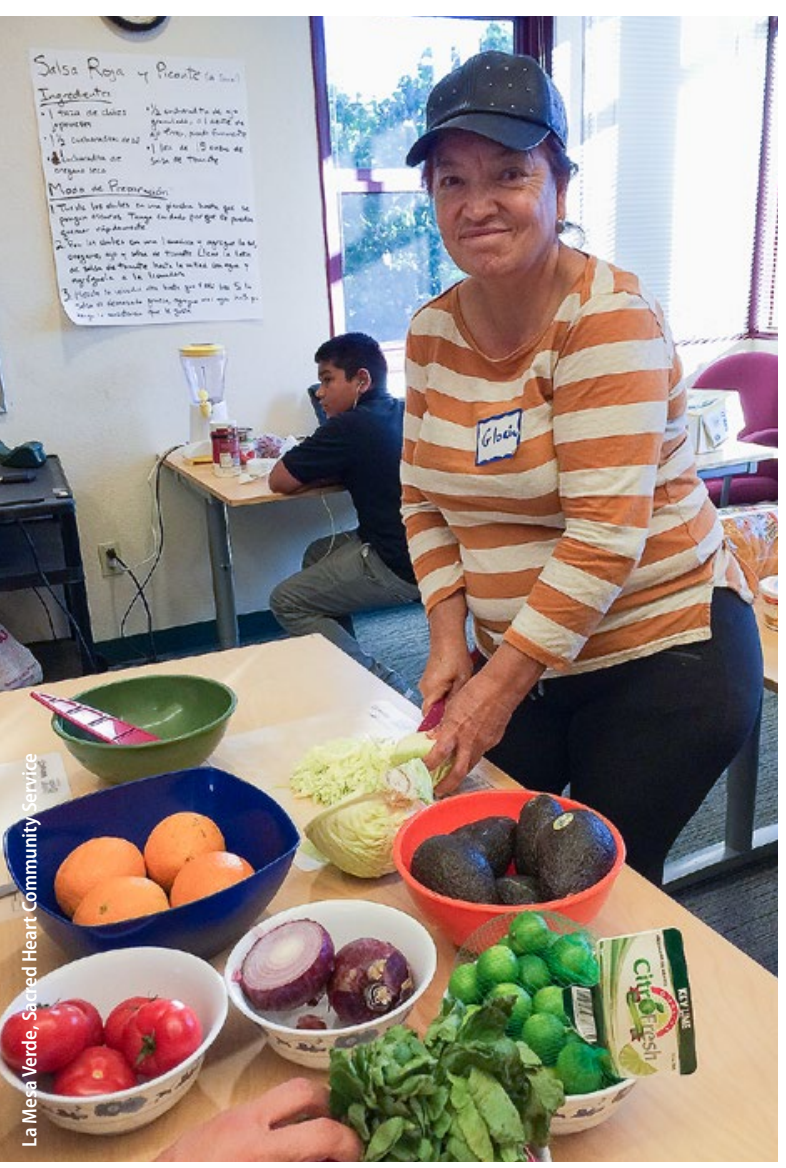

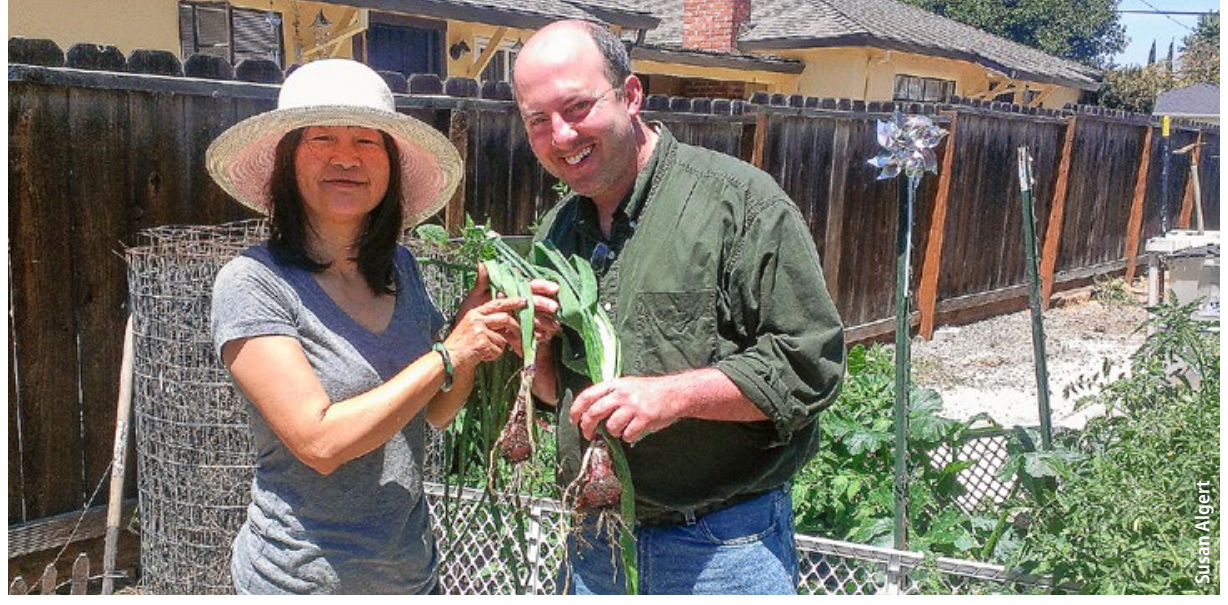

2013, Supplemental Nutrition Assistance Program (SNAP) benefits can also be used to purchase seeds and plants so that low-income households can grow their own produce (Center for the Study of the Presidency and Congress 2012). Thus, both home and community gardens are potentially effective interventions to improve nutrition and food security in lowincome groups, making it important to document the extent to which gardeners, particularly less affluent ones, increase their vegetable intake when eating from their gardens.

In this study, we compare home gardeners in LMV, a program that explicitly targets low-income households, with community gardeners in San Jose, California, and examine whether these two groups increased their vegetable intake while gardening. We also assessed how gardening impacts other elements of food access, such as cost savings, culturally acceptable foods and informal distribution networks. While the community gardeners in our study are on the whole more affluent than LMV gardeners, both groups are ethnically diverse and widely dispersed in neighborhoods throughout the city of San Jose with various levels of food access.

\section{Survey of gardeners in San Jose}

Our study was conducted in partnership with the San Jose Parks, Recreation and Neighborhood Services Department, which runs the city's Community Garden Program, and LMV, a project initiated by Sacred Heart Community Service in 2009. The UC Davis Institutional Review Board approved the study procedures and participants provided informed consent.

San Jose's Community Garden Program has provided gardeners with

The LMV program offers cooking classes to help participants learn how to prepare and cook a meal using produce grown in their gardens. spaces to grow food, socialize and learn about gardening since 1977. Currently, the city operates 18 community gardens that serve more than 900 gardeners and occupy more than 35 acres in total (City of San Jose 2015). Long wait lists for many of the city's gardens show that demand for garden plots greatly exceeds the supply (Public Health Law and Policy 2010).

The goals of LMV include organic food production, cost savings, greater food security, social cohesion and promotion of a healthy lifestyle. In collaboration with Sacred Heart Community Service, UC Master Gardener volunteers provide raised beds, soil, seeds and plants free of charge to families participating in the LMV program. In addition, the volunteers teach introductory organic gardening workshops on topics such as soil science, vegetable cultivation and garden ecology for participating families and make periodic visits to participants' gardens. Participating gardeners are responsible for purchasing fertilizer or soil amendments on their own and paying for water if it is not covered in their rent.

We surveyed 85 community gardeners from four separate community gardens from April through September 2012. We administered the survey (ucanr.edu/u. cfm?id=139) in English or Spanish at the garden sites during times gardeners were working on their plots. Gardeners completed the survey in writing. Prior to the study, the survey was validated on 20 individuals from a single community garden during March 2012.

In addition, we administered the same survey between September 2013 and April 2014 to 50 SNAP-eligible home gardeners participating in the LMV program. Interpreters helped translate the survey into Spanish or Chinese, and it was given to gardeners during community workshops. In total, just under 100 families were enrolled in the LMV program at the time of the survey. Open-ended 
interviews were also conducted with families in LMV to examine program benefits and barriers such as having the resources to maintain soil fertility over time.

The survey obtained background information on the gardeners such as vegetable intake when eating from the garden, cost savings, body mass index (BMI), self-reported health, socio-demographic characteristics and benefits of gardening. BMI was assessed using self-reported weight in kilograms divided by selfreported height in meters squared, and self-reported health was obtained using a question from the Behavior Risk Factor Surveillance System (CDC 2015).

In addition, the survey included two closed-ended questions about (1) distribution of excess produce from the garden to others and (2) benefits of gardening, including meeting with friends and family, fresh air, exercise, stress release and the exchange of ideas with program leaders and other gardeners. Gardeners were also asked to write down their favorite things about gardening and to list the crops grown in their garden, starting with the ones they grow the most.

We assessed vegetable intake with a question from the Expanded Food and Nutrition Education Program (EFNEP) food behavior checklist and used color visuals instead of text to improve readability (Townsend et al. 2012). Participants reported their usual vegetable intake in cups per day. Participants were then asked "Are you eating vegetables from your garden right now?" The third question in this series used color images in place of text to ask gardeners to report how many additional cups of vegetables they consumed when they were eating from the garden. Study participants may have over reported the quantity of vegetables they consumed on a daily basis and when eating from the garden. Bias of over reporting and having no control group are weaknesses of this pilot project.

Descriptive data was summarized as mean and standard deviations, and compared using student $t$-tests for continuous data between the two groups and chisquare analysis for categorical variables.

\section{Profile of gardeners}

The group of home gardeners was younger $(p<0.001)$, lower income $(p<0.001)$, less likely to have completed college $(p<0.001)$ and more ethnically diverse than the group of community gardeners. The average annual income of both the home gardeners $(\$ 26,832)$ and the community gardeners $(\$ 57,600)$ was well below the median annual income $(\$ 95,300)$ in Santa Clara County, where $57 \%$ of households earn more than $\$ 75,000$ each year (Avalos 2014). Educational attainment was also lower among the home gardeners, only $20 \%$ of whom had graduated from college compared to $56 \%$ less (not significant). The home gardeners in this survey were relatively inexperienced because one of the goals of LMV is to train novice gardeners. Seventy percent of LMV participants lived in a house compared to $66 \%$ of community gardeners.

Self-reported health status was similar between the two groups, with $45 \%$ of LMV participants reporting excellent or very good health $(n=22), 35 \%$ reporting

\section{When eating from their gardens, both groups met the U.S. Dietary Guidelines for recommended daily servings of vegetables for adults to promote optimal health}

of community gardeners. The home gardeners were primarily American Indian, Hispanic, mixed race and white, while $53 \%$ of the community gardeners were white (table 1). Most of the American Indian LMV participants were recruited from the Indian Health Center of Santa Clara Valley.

The two study groups also differed in their years of experience as gardeners. Fifty-eight percent of LMV gardeners reported having less than 2 years of experience, whereas only $33 \%$ of community gardeners had gardened for 2 years or good health $(n=17)$ and $20 \%$ reporting fair or poor health $(n=10)$. Thirty-five percent of community gardeners rated their health excellent or very good $(n=23)$, $48 \%$ rated their health good $(n=32)$ and $17 \%$ rated their health fair or poor $(n=11)$. There was no difference in BMI between the two groups of gardeners (table 1), most of whom were overweight.

\section{Effect on vegetable intake}

In spite of their demographic differences, the two groups increased their vegetable consumption to a similar

\begin{tabular}{|c|c|c|c|}
\hline & Home garden & Community garden & Significance \\
\hline Number of participants & 50 & 85 & \\
\hline Gender, female & $42 / 50(84 \%)$ & $42 / 83(50 \%)$ & NS \\
\hline Age, years & $49 \pm 13$ & $58 \pm 12$ & 0.001 \\
\hline Body mass index & $28.5 \pm 6.0$ & $26.3 \pm 5.3$ & 0.058 \\
\hline Monthly income, dollars & $\begin{array}{c}2,236 \pm 1,637 \\
n=37\end{array}$ & $\begin{array}{c}4,800 \pm 3,570 \\
n=51\end{array}$ & 0.001 \\
\hline Race, number of respondents & 25 & 79 & \\
\hline Hispanic & $5(20 \%)$ & $7(9 \%)$ & \\
\hline American Indian & $7(28 \%)$ & $14(18 \%)$ & \\
\hline Black & $1(4 \%)$ & $4(5 \%)$ & \\
\hline Pacific Islander & $1(4 \%)$ & $4(5 \%)$ & \\
\hline White & $6(24 \%)$ & $42(53 \%)$ & \\
\hline Other, mixed & $5(20 \%)$ & $8(10 \%)$ & \\
\hline Residence, house & $35 / 50(70 \%)$ & $56 / 85(66 \%)$ & \\
\hline Education, number of respondents & 47 & 82 & 0.001 \\
\hline Less than high school & $10(21 \%)$ & $8(10 \%)$ & \\
\hline High school graduate & $6(12.5 \%)$ & $5(6 \%)$ & \\
\hline Some college & 21 (44\%) & $24(30 \%)$ & \\
\hline College graduate, or post graduate & $10(20 \%)$ & $45(54 \%)$ & \\
\hline
\end{tabular}


gardeners explained that gardening made them feel part of a community; they described developing a network of fellow gardeners through the workshops and services offered by LMV and connecting with their neighbors by sharing produce, work and knowledge about gardening. When asked how gardens would change the neighborhood, one participant replied that houses with gardens would look less abandoned.

Community gardeners said their top benefits were exercise, meeting with friends and learning from other gardeners. Open-ended survey responses of community gardeners also emphasized the feelings of community and sharing they experienced when working in the garden. Gardeners appreciated spending time with neighbors, friends and family in their gardens; these interactions were a source of happiness, friendship and learning. The community gardeners also saw their gardens as a source of healthy food, reporting that their gardens gave them the opportunity to have food that was fresh, organic and more nutritional than its store-bought counterpart.

Learning about gardening as a family was emphasized by the home gardeners, whereas learning about gardening from garden leaders and friends was stressed by those using community garden plots. Similarly, other studies have shown that community gardens provide a space and activity around which to socialize and develop social networks (Carney et al. 2012; Harris et al. 2014; Pitt 2014; Zick et al. 2013).

\section{Increasing vegetable consumption}

The results of this small pilot study indicate that both community and home gardeners substantially increased their vegetable intake when eating from their gardens. Although the gardeners surveyed differed in their income level, educational attainment, ethnic background and level of gardening experience, we found that gardening in either a community or backyard space made a significant contribution to gardeners' daily vegetable intake.

The findings from this research which, to our knowledge, is the first to

\footnotetext{
At the time of the survey, $79 \%$ of home gardeners and $63 \%$ of community gardeners reported that they were eating vegetables from their gardens.
}

obtain data on the number of portions of vegetables consumed by gardeners when they are eating from their gardens - are consistent with other studies of the nutritional impacts of gardening. A recent study analyzing the output of a model raised bed garden designed for a family of four found that it produced 2.45 vegetable servings per person per day, providing essential vitamins and minerals (Fruge et al. 2014). A study of home and community gardeners in Denver, Colorado, found that gardeners ate fruits and vegetables more times per day than non-gardeners (Litt et al. 2011). Other researchers have shown that the most significant impact of home food gardening on food security was its ability to enhance gardeners' access to fresh produce and improve the nutritional value of their diets by increasing the diversity of fresh produce consumed (Kortright and Wakefield 2010).

Gardening has been associated with a healthier diet and lower BMIs (Alaimo et al. 2008; Litt et al. 2011; van den Berg et al. 2010; Wakefield et al. 2007; Zick et al. 2013). Although participants in our study were overweight, the majority reported good to excellent health. In a previous study of LMV, program participants said they had changed their eating habits and were incorporating more fruits and vegetables into their diet while reducing fast food consumption (Gray et al. 2013).
A Philadelphia study demonstrated that gardeners consumed more vegetables such as dark leafy greens and fewer sweet foods and drinks than did non-gardeners (Blair et al. 1991). Further research on the nutritional intake of gardeners is needed to demonstrate whether they have a healthier diet overall.

Creating access to food specific to a gardeners' heritage is often the motivation for growing particular crops. In this study, participants reported growing cultural or ethnic foods such as bok choy, gogi berries, chayote and green tomatoes. Similar to other research projects, many families in this study grew foods that had meaning in terms of their identity as individuals and their personal and community history (Fruge et al. 2014; Schupp and Sharp 2012). The agrobiodiversity of the garden contributes to nutrition and food security by increasing the intake of culturally unique vegetables. Gardens also allow family members to pass culturally relevant knowledge to others such as children, grandchildren and neighbors.

The finding that excess food from both the community and home gardens was given to friends and family suggests that the health benefits of gardens extend beyond what the gardeners themselves experience. A greater understanding of reciprocity networks in the garden and their contribution to nutrition and food

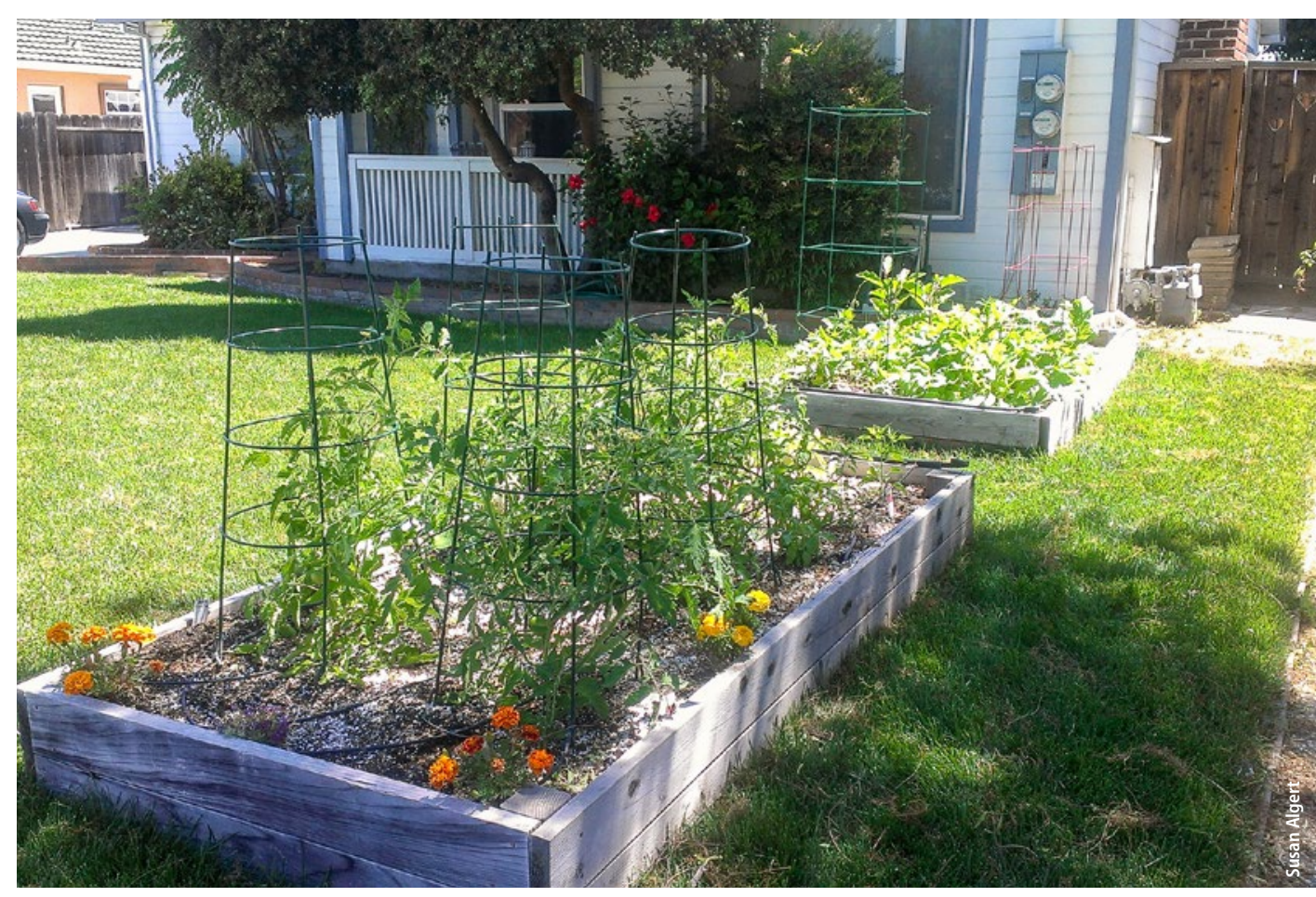


security for an extended network of family and friends should be explored further (Schupp and Sharp 2012).

Limitations of our study include the small sample size, the unknown degree of bias due to self-selection and the potential for recall bias in self reporting. Populations were self-selected based on their interest in gardening; we expect the bias would be equal between the two populations of gardeners. Vegetable intake, health status and BMI are selfreported and subject to recall bias. Gardeners may have over reported the amount of vegetables they consume on a daily basis and the amount of vegetables they consume when eating from their gardens. Cultural differences in interpretation of questions makes administering pilot surveys challenging, particularly for non-English-speaking survey participants. For example, the use of translators to administer surveys in Chinese and Spanish may have led to confusion among the gardeners about the interpretation of some questions. Given that this was a pilot study, the results should be considered exploratory and suggest areas for future research.

At present more than a third of all households, or 42 million households, in America are growing food at home or in a community garden. This represents a $17 \%$ increase overall from 2008, when 36 million households were food gardening. The largest increase in participation is among younger households, up $63 \%$ to 13 million since 2008. Over the same period, participation also increased $25 \%$ by households with children (up to 15 million in 2013), $29 \%$ by people in urban areas (up to 9 million) and $38 \%$ by households with incomes under $\$ 35,000$ (up to 11 million) (National Gardening Association 2014). As our pilot study indicates, both community and home gardens are an effective public health mechanism to increase local opportunities to consume more fresh produce. Particularly when provided with resources and training as in the LMV program in San Jose, even novice gardeners can learn to grow their own vegetables.

Significant barriers to residential food production must be addressed, however.
These include the lack of gardening skills and the need for secure access to suitable land on which to grow food (Baker et al. 2013; Litt et al. 2011). In addition, costs associated with initiating and maintaining community and home gardens can be substantial, particularly for low-income families, and future research should investigate the relative cost-effectiveness of urban gardens and other strategies for increasing residents' access to fresh produce. CA

S. Algert is UC ANR Cooperative Extension Nutrition, Family and Consumer Sciences Advisor in San Francisco, San Mateo and Santa Clara counties (retired); L. Diekmann is AFRI NIFA Postdoctoral Researcher in the Food and Agribusiness Institute at Santa Clara University; M. Renvall is Private Consultant (retired from UC San Diego Department of Medicine); L. Gray is Associate Professor in the Department of Environmental Studies and Science at Santa Clara University.

Lucy Diekmann's participation in this study was funded by an AFRI NIFA postdoctoral fellowship.

\section{References}

Alaimo K, Packnett E, Milers RA, Kruger DJ. 2008. Fruit and vegetable intake among urban community gardeners. J Nutr Educ Behav 40(2):94-101.

Algert SJ, Baameur A, Renvall MJ. 2014. Vegetable output and cost savings of community gardens in San Jose, CA. Acad Nutr Diet 114:1072-76.

Avalos G. 2014. Santa Clara County has highest median household income in nation, but wealth gap widens. August 11, San Jose Mercury News.

Baker EA, Motton F, Seiler R, et al. 2013. Creating community gardens to improve access among African Americans: A partnership approach. J Hunger Env Ntrn 8:516-32.

Blair D, Giesecke CC, Sherman SA.1991. Dietary, social and economic evaluation of the Philadelphia Urban Gardening Project. J Nutr Educ 23(4):161-67.

Carney PA, Hamada JL, Rdesinski R, et al. 2012. Impact of community gardening project on vegetable intake, food security and family relationships: a communitybased participatory research study. J Commun Health 37:874-81.

[CDC] Centers for Disease Control and Prevention. Behavioral Risk Factor Surveillance System Survey Questionnaire. Atlanta GA: Centers for Disease Control and Prevention. www.cdc.gov/brfss/ (accessed February 2, 2015).

Center for the Study of the Presidency and Congress. 2012. SNAP to Health: A Fresh Approach to Strengthening the Supplemental Nutrition Assistance Program.

City of San Jose. 2015. Community garden plots. www. sanjoseca.gov/index.aspx? NID=599 (accessed June 21, 2015).

Coleman-Jensen A, Nord M, Andrews M, Carlson S. 2012. Household Food Security in the United States in 2011. ERR141. U.S. Department of Agriculture, Economic Research Service.
Fruge AD, Byrd SH, Melby P, et al. 2014. The economic and nutritive value of the raised bed home vegetable garden: a model for the southeastern United States. Food Studies 3(2):1-9.

Gray L, Guzman P, Glowa KM, et al. 2013. Can home gardens scale up into movements for social change? The role of home gardens in providing food security and community change in San Jose California. Local Environ 19(2):187-203.

Haack SA, Byker CJ. 2014. Recent population adherence to and knowledge of United States federal nutrition guides, 1992-2013: a systematic review. Nutr Rev 72 (10):613-26.

Harris N, Minnis FR, Somersat S. 2014. Refugees connecting with a new country through community food gardening. Int J Environ Res Public Health 11:9202-16.

Hiza HAB, Casavale KO, Guenther PM, et al. 2013. Diet quality of Americans differs by age, sex, race/ethnicity, in come and education level. J Acad Nutr Diet 113:297-306. Kirkpatrick SI, Dodd KW, Reedy J, et al. 2012. Income and race/ethnicity are associated with adherence to food based dietary guidance among US adults and children. J Acad Nutr Diet 112: 624-35.

Kortright R, Wakefield R. 2010. Edible backyards: a qualitative study of household food growing and its contributions to food security. Agric Hum Values 28:39-53. doi:10.1007/s10460-009-9254-1.

Litt JS, Soobader MJ, Turbin MS, et al. 2011. The influence of social involvement, neighborhood aesthetics, and community garden participation on fruit and vegetable consumption. Am J Public Health 101:1466-73.

National Gardening Association. 2014. Food gardening in the U.S. at the highest levels in more than a decade according to new report by the National Gardening Association. http://assoc.garden.org/press/press. php?q=show\&pr=pr_nga\&id=3819 (accessed February 2, 2015).
Pitt H. 2014. Therapeutic experiences of community gardeners: putting flow in its place. Health Place 27:84-91.

Public Health Law and Policy. 2010. Healthy food assessment for Santa Clara County. Oakland, CA: Public Health Law and Policy.

Schupp JL, Sharp JS. 2012. Exploring the social basis of home gardening. Agric Hum Values 29:93-105.

Taylor JR, Lovell ST. 2012. Mapping public and private spaces of urban agriculture in Chicago through the analysis of high-resolution aerial images in Google Earth. Landscape Urban Plan 108:57-70.

Taylor JR, Lovell ST. 2014. Urban home food gardens in the global north: research traditions and future directions. Agric Hum Values 31:285-305.

Townsend M, Donohue S, Roche B, et al. 2012. Designing a food behavior checklist for EFNEP's low literate participants. J Nutr Educ Behav 44:S74-S75.

[USDA DHHS] US Department of Agriculture and US Department of Health and Human Services. 2010. Dietary Guidelines for Americans, 2010 (7th ed.). www.health. gov/dietaryguidelines/dga2010/dietaryguidelines2010. pdf (accessed January 30, 2015).

van den Berg $A E$, van Winsum-Westra $M$, de Vries $S$, et al. 2010. Allotment gardening and health: a comparative survey among allotment gardeners and their neighbors without allotment. Environ Health 9:74. doi:10.1186/1476-069X-9-74.

Wakefield S, Yeudall F, Taron C, et al. 2007. Growing urban health: community gardening in southeast Toronto. Health Promot Int 22(2): 92-101.

Zick CD, Smith KR, Kowaleski-Jones L, et al. 2013. Harvesting than vegetables; the potential weight control benefits of community gardening. Am J Public Health 103:1110-15. 